\title{
LA DISLEXIA: BASES TEÓRICAS PARA UNA PRÁCTICA EFICIENTE ${ }^{1}$
}

\section{DYSLEXIA: THEORETICAL BASIS FOR AN EFFICIENT PRACTICE}

\author{
Marisol Carillo \\ Universidad de Murcia, España
}

Palabras clave: psicolingüística, dislexia, lectura

Keywords: psycholinguistics, dyslexia, reading

Buenas tardes, siento un especial agrado por tener una nueva oportunidad de visitar esta Universidad en la que estuve por primera vez en 2007, coincidiendo con el Congreso organizado en aquellas fechas por la Sociedad Uruguaya de la Dislexia en torno a la lectura. Iniciábamos entonces relaciones internacionales para intercambio de estudiantes de Psicopedagogía y Educación Inicial entre esta Universidad y la Universidad de Murcia a la que yo pertenezco. Quiero aprovechar esta ocasión para animar al alumnado presente a participar en el programa y seguir algún curso en mi universidad, en la que serán acogidos con el mismo cariño que mis alumnas y yo somos acogidos aquí.

Agradezco a los profesores Ariel Cuadro y Daniel Trías esta invitación que me da la oportunidad de estrechar aún más los lazos profesionales y personales que mantengo con ellos y con otras profesoras de esta Universidad. Es gracias a estos lazos que me siento cómoda y feliz de encontrarme aquí, de nuevo en este imponente espacio, dispuesta a compartir con ustedes mi visión del problema de la dislexia.

Desde hace más de 20 años mi tema de investigación es la adquisición de la lectura y las dificultades en este aprendizaje, pero la base de mi interés y formación es anterior, viene de mi experiencia como maestra, maestra de educación infantil. Esta es la razón por la que mis primeras investigaciones fueron sobre el desarrollo de la conciencia fonológica y posteriormente se ampliaron al estudio de la dislexia que es el tema que hoy nos ocupa. También quiero señalar que poco después de que en mi grupo comenzáramos a investigar la dislexia, compartimos este interés y nuestra experiencia con el profesor
Ariel Cuadro, lo que dio lugar a su tesis doctoral investigando sobre el tema aquí en Uruguay. Realmente en aquellos momentos se había investigado poco sobre la dislexia en castellano.

Hoy día, el conocimiento científico sobre la dislexia es sólido, son decenas de años investigando en este problema en distintas lenguas y yo creo que las aportaciones en los últimos diez años han sido decisivas para entender mucho mejor esta dificultad y sus causas. A pesar de ello, la dislexia es un problema tan complejo que aún queda mucho por investigar, sobre todo en lo que concierne a su tratamiento educativo. Son numerosos los profesionales que tienen que tratar con disléxicos y aún hoy no saben cómo hacerlo. Yo voy a tratar de clarificar algunas ideas que me parecen bien consolidadas en la actualidad y que orientan sobre el camino a seguir en la intervención. Para los investigadores es un logro cuando con nuestro trabajo conseguimos entender mejor el problema, pero cuando tratamos que ese logro transcienda a la práctica y redunde en beneficio de esos niños, la distancia que hay que recorrer es todavía demasiado larga. Se hace imprescindible el buen hacer de los profesionales que se encargan de la educación de esos niños, porque lo realmente importante no es el logro de la investigación sino cómo ese logro es luego aplicado, utilizado por los educadores que hacen el tratamiento de esos niños. Esa es la empresa más complicada que nos queda por alcanzar y que constituye la meta, aún lejana, de nuestros esfuerzos.

Voy a comenzar con una definición de dislexia del desarrollo, de una gran aceptación entre los investigadores, y vamos a analizarla brevemente: 
La dislexia es una dificultad específica de aprendizaje de origen neurológico. Se caracteriza por dificultades de precisión y fluidez en el reconocimiento de palabras escritas y por problemas en la descodificación y el deletreo. Estas dificultades son causadas por un déficit en el componente fonológico del lenguaje, de carácter inesperado, dado que otras habilidades cognitivas tienen un desarrollo normal y la enseñanza es adecuada (Asociación Internacional de Dislexia, 2002).

En primer lugar "la dislexia es una dificultad específica de aprendizaje". El término dificultad específica de aprendizaje es importante porque nos señala que esta dificultad ocurre con independencia de otros aprendizajes en los que no tienen problemas los disléxicos. Se trata por tanto de una dificultad de aprendizaje que no afecta a otras áreas, y de ahí el calificativo de "específica". Además, la definición incluye que la dificultad es "de origen neurológico"; este carácter biológico ha sido muy debatido y en el pasado resultaba inaceptable para muchos educadores. Parecía que aceptar este origen negaba la posibilidad de cualquier recuperación a través del tratamiento psicopedagógico. Pero en los últimos años, las posibilidades de estudiar el cerebro en acción, de estudiar el funcionamiento cerebral en los procesos de lectura, han aportado la evidencia científica de esta realidad. Se ha observado que hay una disfunción en el cerebro del disléxico, justamente en las áreas en las que se procesan las palabras escritas, y que ese problema deriva de disfunciones en la maduración cerebral presentes ya en el nacimiento del disléxico.

En segundo lugar, la dislexia "se caracteriza por la dificultades de precisión y fluidez en el reconocimiento de palabras escritas y por problemas en la descodificación y el deletreo". Hemos de considerar que las dificultades manifestadas en la precisión o exactitud, son lo que hasta hace poco se esperaba de los disléxicos, pero las investigaciones realizadas en lenguas más transparentes que el inglés, como el alemán, el italiano o el castellano, señalan que no sólo los errores en la lectura son indicadores de la dislexia, también la falta de fluidez caracteriza los problemas de los disléxicos en el reconocimiento de las palabras escritas. En nuestros primeros estudios en castellano nos sorprendió que los disléxicos, a pesar de su grave retraso en la lectura, no cometieran muchos errores en la lectura de palabras aisladas, incluso en la lectura de pseudopalabras. Así pues, es importante considerar también como característica de la dislexia la falta de fluidez, indicativa de una deficiencia en la automatización del procesamiento de las palabras que entorpece la comprensión de lo que se lee. Cuando observamos la lectura de palabras de un niño disléxico con varios años de aprendizaje de la lectura, sobre todo en lenguas transparentes como el castellano, solemos encontrar un considerable conocimiento de las correspondencias grafo-fonológicas que les permite una lectura con pocos errores. La adquisición de este conocimiento le ha llevado mucho tiempo y considerable esfuerzo y le sigue siendo costoso aplicarlo cuando lee, por ello la fluidez todavía es baja, no lee las palabras automáticamente y eso impide que pueda comprender lo que está leyendo. Consecuentemente, es importante que la definición de dislexia recoja el problema de falta de fluidez.

En tercer lugar, y con referencia a la causa cognitiva del trastorno, la definición plantea que el problema es producto de un déficit en el componente fonológico del lenguaje. Esta inclusión diferencia a esta definición de las definiciones clásicas de exclusión, que no identifican el déficit característico de la dislexia. Aunque pueda haber dificultades de lectura causadas por trastornos en otras capacidades, el modelo más aceptado actualmente reserva el término dislexia a las dificultades que tienen su origen en algún aspecto del procesamiento de los sonidos del lenguaje.

Finalmente, la definición añade que este problema ocurre de manera inesperada, dado que esos niños no tienen otros problemas cognitivos, o falta de asistencia a clase, o una mala enseñanza de la lectura. Esto le ocurre a niños que van a clase habitualmente, que tienen interés por aprender a leer, que cognitivamente son inteligentes, que aprenden matemáticas, que aprenden otras cuestiones, sin embargo cuando tienen que aprender la lectura se encuentran con esa grave dificultad. Ese carácter de inesperado es interesante porque nos ayuda a entender la dislexia y a la persona disléxica.

Después de esta primera aproximación, voy a intentar clarificar lo que hoy sabemos sobre las causas de la dislexia. Hace algunos años, 
en 1999, Uta Frith publicó un artículo en el que propone un esquema que permite integrar las diferentes teorías causales de la dislexia. Este esquema sitúa cada teoría en un determinado nivel explicativo, lo que ha resultado muy clarificador tanto para mí como para otros investigadores. Se incluyen tres niveles de descripción de la dislexia: biológico, cognitivo y comportamental que facilitan su comprensión. Podemos explicar las causas de la dislexia desde un nivel biológico, entendiendo que la dislexia es un problema neurológico con base genética y que por tanto está ya presente en el momento de nacer, aunque las dificultades se manifiesten mucho más tarde. Ese daño biológico, que afecta a áreas cerebrales precisas en el hemisferio cerebral izquierdo, tiene repercusiones a nivel cognitivo al provocar un déficit fonológico que por su parte será la causa inmediata de las dificultades para establecer conexiones grafema-fonema. Finalmente, en el nivel comportamental, las consecuencias del déficit fonológico serán las enormes dificultades del disléxico con la lectura, su pobre desarrollo metafonológico así como sus posibles dificultades en velocidad de nombrado y en memoria fonológica.

Hay teorías que abordan la explicación de la dislexia en el nivel biológico, mientras que otras se sitúan en el nivel cognitivo, sin embargo, si nuestro propósito es comprender el problema de cara a su tratamiento recuperador, resulta poco útil saber qué genes son los responsables o qué área del cerebro está afectada. Esta información, dentro del diagnóstico de la dislexia, no aporta indicaciones para el tratamiento. En realidad, el trabajo más interesante de la dislexia se ha hecho desde el plano de la Psicología Cognitiva. Los avances más importantes, hoy por hoy, siguen siendo los que nos han ayudado a entender cómo funciona el cerebro disléxico en el nivel cognitivo, cuáles son los procesos que están afectados, y porqué el déficit fonológico tiene tan graves repercusiones en la lectura.

Siguiendo este esquema, al disléxico lo podríamos caracterizar o diagnosticar a tres niveles: a nivel biológico, identificando el área de su funcionamiento cerebral que está afectada; a nivel cognitivo identificando su déficit fonológico; y a nivel conductual identificando los fallos cuando lee. Una completa identificación de los procesos deficitarios en la lectura y una interpretación de sus posibles causas inmediatas, de acuerdo con los modelos de procesamiento lector, es la base necesaria para el diseño de un tratamiento recuperador.

Además, una consecuencia práctica del hecho de que la dislexia esté presente antes de que sus síntomas aparezcan con el aprendizaje de la lectura es la posibilidad de evaluar el déficit fonológico con tareas adecuadas a pre-lectores, por ejemplo, con tareas de conciencia fonológica, de nombrado de imágenes o de memoria fonológica. La detección de algún déficit en estos procesos abre la posibilidad de un tratamiento preventivo y de planificar la enseñanza de la lengua escrita atendiendo a las dificultades detectadas en los aprendices.

También quiero señalar otras breves reflexiones a propósito de caracterizar la dislexia en los tres niveles citados. Se trata de pensar en la posibilidad de ser disléxico incluso sin haber aprendido a leer, y en el hecho de que la identificación de casos de dislexia tienda a aumentar en la medida en la que aumenta la proporción de personas que acceden a la escolaridad. Además, en la medida que aumentan los niveles de dominio de la lengua escrita que se espera que alcancen todos los escolares en la enseñanza obligatoria, se irán haciendo más visibles los problemas de muchos disléxicos y no disléxicos con el aprendizaje de la lectura.

Por otra parte, al aumentar la visibilidad de la dislexia aumenta la necesidad de que la escuela responda a las necesidades educativas de los aprendices que la padecen.

En España asistimos en los últimos años a la publicación de las normativas destinadas a la obligada atención específica a los escolares disléxicos recogida en la actual ley de Educación (LOE). Igualmente se ha producido una mayor movilización de las asociaciones de padres de niños disléxicos, quienes demandan los derechos de sus hijos a ser atendidos con medidas pedagógicas adecuadas dentro del sistema educativo, de la misma manera que reciben apoyo especializado los niños que presentan deficiencia visual, deficiencia auditiva, hiperactividad, o incluso altas habilidades. Es notable que aún hoy muchas Comunidades Autónomas en España carezcan de esta normativa y se mantenga sin precisar la atención especializa- 
da a los escolares con dislexia. Sin duda, aún queda mucho por hacer para informar a las autoridades de la importancia del problema, para explicar el grave trastorno que padecen los disléxicos y de las nefastas consecuencias que la falta de un diagnóstico y la consecuente ayuda educativa tiene para las vidas de estos niños.

Hemos hablado de la importancia del nivel cognitivo en la explicación de la dislexia, y será en este nivel en el que nos centraremos a continuación. ¿Qué es lo que sabemos desde la Psicología Cognitiva sobre el procesamiento de las palabras escritas? ¿Por qué fallan los disléxicos? La impresión del lector experto es que la identificación de las palabras es algo sencillísimo, fácil, rápido e inmediato y que no podría ser analizado; simplemente hay una palabra e instantáneamente uno la lee. ¿Qué puede haber pasado en los escasos milisegundos que se tarda en leer una palabra?, ¿qué procesos han permitido reconocerla?, ¿en qué ha fallado el disléxico que no ha sido capaz de reconocerla con exactitud y rapidez? Las explicaciones dadas en el pasado estaban basadas en la idea de que el procesamiento de las palabras escritas era una tarea meramente visual, ya que los estímulos son gráficos. Por tanto los problemas de los disléxicos deberían estar en la discriminación visual de las letras, y provenían de problemas básicos en orientación espacial, confusiones entre derecha e izquierda, etc. Pero los modelos de procesamiento lector surgidos de la investigación cognitiva, han puesto al descubierto que la identificación de palabras es en sí una tarea compleja, descomponible en etapas de procesamiento. $Y$ que el problema fundamental de los disléxicos no está en el tratamiento de la forma gráfica de las letras, sino que reside en lo que ellas representan. Las letras representan los sonidos elementales de las palabras, representan a los fonemas, pero los fonemas no son fáciles de identificar en la producción de las palabras ya que se producen coarticulados entre sí. Para aislarlos es preciso desarrollar lo que se ha denominado conciencia fonológica y los disléxicos tienen grandes problemas para este desarrollo debido a sus problemas con la fonología. Aislar los fonemas para entender lo que representan las letras es una de las tareas más complicadas para el aprendiz. Los prelectores son incapaces de hacerlo, pero lo conseguirán con relativa facilidad si en el comienzo del aprendizaje de la lectura cuentan con representaciones fonológicas precisas de las sílabas y palabras y se ayudan de la representación gráfica secuenciada de las letras que las forman. Es así que llegan a entender que en una palabra como "gato" hay cuatro sonidos y qué letra de la palabra escrita representa a cada uno de ellos.

Por otra parte, la investigación cognitiva ha mostrado que el tiempo empleado en reconocer las palabras es diferente dependiendo de algunas de sus características, como por ejemplo su frecuencia de uso. El hecho de que una palabra de alta frecuencia se reconozca más rápido que otra de baja frecuencia indica que se han procesado de manera diferente. También la diferencia en el tiempo de identificación de palabras según existan o no palabras muy similares a ellas (vecinas) indica la complejidad del procesamiento en el que tiene cabida la influencia de esta y de otras variables. Todos estos estudios nos han permitido comprender, con un alto grado de finura, cuáles son los mecanismos que intervienen en la identificación de palabras y también averiguar dónde se producen los fallos en los disléxicos.

Al hablar de los mecanismos en la lectura de palabras me refiero a lo que también se conoce como rutas de procesamiento. El primer mecanismo es el utilizado cuando se trata de palabras (y pseudopalabras) no familiares en su forma escrita para el lector, y requiere la aplicación de correspondencias grafo-fonológicas y el ensamblado de las unidades fonológicas obtenidas. La identificación de la palabra y el acceso a su significado se logra a través de la forma sonora de la palabra por lo que se le denomina mecanismo o ruta fonológica.

Se trata de un mecanismo muy importante en los momentos iniciales del aprendizaje de la lectura, y en el que algunos aprendices ya comienzan a tener dificultades lo que les impide seguir progresando. Algunos de ellos necesitarán más tiempo y apoyo para lograrlo, otros, los disléxicos, puede que no consigan nunca aplicar con exactitud y rapidez las correspondencias grafo-fonológicas. Los maestros suelen detectar muy prontamente estos casos, pero pueden no comprender las razones de tal dificultad cuando ocurren en aprendices que 
no presentan otras dificultades en su desarrollo cognitivo y en otros aprendizajes. Cuando se detectan estos casos, la intervención debe comenzar inmediatamente ya que se trata de una dificultad que impide seguir avanzando en la lectura. El apoyo debe basarse en el desarrollo de la conciencia fonológica y la consolidación progresiva de las correspondencias grafema-fonema.

En el segundo mecanismo de lectura es el acceso directo o ruta visual-ortográfica lo que se pone en funcionamiento, y ocurre cuando la palabra es ortográficamente familiar para el lector y puede reconocerla visualmente sin necesidad de ensamblar su fonología. Para diferenciar entre el mecanismo fonológico y el mecanismo ortográfico es útil comparar nuestra experiencia al leer pseudopalabras tales como "tesmar", "Vimondeote" y "ulaz" y al leer las palabras "martes", "Montevideo" y "azul". Las primeras están formadas reordenando las sílabas que componen las segundas, por lo que no se diferencian en longitud ni en complejidad de sus sílabas. Sin embargo, esas palabras inventadas han requerido más tiempo para ser leídas porque ha sido necesario aplicar el mecanismo de conversión y ensamblado grafo-fonológico, mientras que las palabras que ya nos eran familiares las hemos reconocido directamente.

El mecanismo fonológico es, por tanto, necesario para leer las palabras escritas que vemos por primera vez. Si pensamos en el aprendiz que comienza a leer, nos damos cuenta, que son muchas las palabras nuevas que encuentra en sus materiales de lectura y que requieren la aplicación del mecanismo fonológico. Sin este mecanismo será imposible que el niño lea correctamente estas palabras. Pero, además, tampoco podrá disponer del mecanismo ortográfico porque tal mecanismo sólo funciona con las palabras de las que ya disponga de representaciones ortográficas en su léxico. La forma en la que se adquieren representaciones ortográficas, ha sido objeto de múltiples investigaciones que han dado lugar al Modelo de auto-enseñanza propuesto por David Share en 1995. La idea básica del modelo es que cuando una palabra, en principio no familiar ortográficamente para el lector, es leída varias veces utilizando el mecanismo de recodificación fonológica, la secuencia de las letras que forman la palabra es memorizada en el léxico ortográfico y podrá ser activada en las posteriores lecturas y reconocida por medio del mecanismo ortográfico. Los progresos hacia una lectura fluida dependen de que buena parte de las palabras que integran un texto puedan ser reconocidas de forma rápida y directa a través del mecanismo ortográfico. De esta forma quedarán recursos suficientes para llevar a cabo los procesos necesarios para la comprensión del texto. Así pues, la comprensión depende en buena medida de que la identificación de las palabras se realice de forma rápida y sin esfuerzo, tal como permite el mecanismo ortográfico de lectura.

Estos dos mecanismos fallan de forma más o menos grave en el disléxico, dando lugar a diferentes perfiles de déficit que, en sus casos más extremos, han permitido identificar diferentes subtipos de dislexia. Algunos estudios realizados con disléxicos de lengua castellana, entre ellos los realizados por mi grupo de investigación en España y por el grupo de Ariel Cuadro en Uruguay, muestran casos de disléxicos con problemas más acusados en la aplicación del mecanismo fonológico que en la del ortográfico (perfil fonológico) y casos con la descompensación contraria (perfil de superficie u ortográfico), sin embargo la descompensación no parece ser estable sino que va evolucionando con el nivel y la experiencia lectora. Los resultados en estos estudios indican que la diferenciación entre subtipos no sería consecuencia de diferencias estructurales en el procesamiento lector. También en los disléxicos el desarrollo del mecanismo ortográfico dependería del desarrollo del fonológico, según el modelo de Share comentado anteriormente, si bien con la edad y la experiencia lectora los disléxicos podrían adoptar estrategias de lectura para compensar su déficit en el mecanismo fonológico.

Al considerar que el mecanismo fonológico es el motor del progreso en el desarrollo lector y que este mecanismo falla tempranamente en los disléxicos, cabe preguntarse cómo evolucionan estos aprendices con dificultades. Son muchos los factores influyentes, en primer lugar la gravedad del déficit fonológico pero también si recibe o no apoyo educativo especializado, el propio interés y motivación del aprendiz, sus capacidades lingüísticas 
e intelectuales y por otra parte el progreso también dependerá del grado de consistencia y simplicidad de las correspondencias grafofonológicas de la ortografía de su lengua. Por ejemplo, en castellano estas correspondencias son simples y totalmente consistentes, por lo que se califica de transparente a su ortografía, sin embargo el inglés tiene una ortografía opaca con reglas complejas de correspondencia y abundantes inconsistencias o irregularidades. Consecuentemente, la lectura en castellano es más fácil de aprender incluso para los disléxicos. No obstante el grado de dificultad que encuentre el disléxico en esta lengua también dependerá de la gravedad de su déficit fonológico. En general, logran aprender las correspondencias pero no consiguen aplicarlas de forma automática y sin esfuerzo y tampoco logran adquirir representaciones ortográficas de las palabras de suficiente calidad. No obstante los disléxicos pueden mejorar si reciben un tratamiento adecuado a sus dificultades.

En resumen, el análisis experimental de los procesos cognitivos implicados en la identificación de palabras escritas y en el aprendizaje de la lectura demuestra el papel esencial del mecanismo de conversión grafo-fonológica, mecanismo que depende del desarrollo de la conciencia fonológica. Pero también otros aspectos del procesamiento fonológico relacionados más lejanamente con la lectura suelen estar afectados en los disléxicos, lo que hace más amplias y graves sus debilidades fonológicas. Las dificultades pueden afectar a la calidad de las representaciones fonológicas (p.ej. problemas de discriminación fonética), también a la velocidad con la que se accede a ellas (problemas en el nombrado rápido) o a la capacidad para mantenerlas en la memoria a corto plazo. Estas dificultades afectan por tanto de forma directa al procesamiento de la lengua oral, aunque sus consecuencias no dificulten gravemente la comunicación. Si hace unos años se caracterizaba al disléxico exclusivamente por sus problemas con la lengua escrita, en la actualidad también se reconocen sus dificultades sutiles con la fonología en la lengua oral. Pequeñas dificultades en discriminar entre /po/ y /bo/ pueden causar confusiones entre algunas palabras como "polo" y "bolo", pero al escuchar estas palabras en un contexto significativo no provocará problema de comunicación ya que el significado podrá ser identificado. Sin embargo estas dificultades tienen consecuencias en el aprendizaje de las correspondencia grafo-fonológicas, porque no permiten establecer una correspondencia estable y diferenciada del fonema /b/ con su grafema "b" (o " $v$ ") y del fonema /p/ con su grafema "p". Para entender mejor este problema de los disléxicos, resulta orientativo situarlo en el ámbito musical, por ejemplo en la discriminación de dos notas musicales como "Re" y "Mi"; aunque podamos percibir que ambas notas son diferentes podemos tener dudas sobre la identidad de cada una de ellas al escucharlas aisladamente. Probablemente, si carecemos de suficientes conocimientos musicales, elegiremos al azar entre las dos opciones, tal como hacen algunos disléxicos antes los fonemas /b/ y /p/.

En relación con las dificultades de los disléxicos para localizar palabras concretas en su léxico, por ejemplo cuando han de recordar el nombre de un actor o se les pide decir nombres de animales durante 20 o 30 segundos, el problema no deriva de una falta de vocabulario, ellos pueden conocer decenas de ellos, lo que les cuesta es acceder a sus nombres de manera eficaz. Saben los nombres pero tardan en responder.

Estos componentes o aspectos del tratamiento de la fonología son los que se han estudiado en los últimos años y se ha mostrado que son deficientes en los disléxicos, aunque la gravedad de sus problemas no sea la misma en todos ellos. El problema fonológico más grave se produce cuando afecta a la entrada de la información fonológica, ya que si no se es capaz de diferenciar y categorizar correctamente los fonemas, las representaciones que se almacenen serán imprecisas y ello tendrá consecuencias cuando se deban utilizar tales representaciones, por ejemplo en el análisis fonémico de las palabras y en establecimiento de correspondencias grafema-fonema.

Así, cuando hablamos de representaciones fonológicas nos referimos al conocimiento lingüístico sobre la fonología de palabras, sobre los fonemas y su secuencia que están almacenados en la memoria y que los tenemos que utilizar, por ejemplo para nombrar imágenes, evocar el nombre de algo, accediendo a ellos sin dificultades. Estas representaciones 
y procesos no son específicos de la lectura, no hay que leer nada, implican a la lengua oral, pero la lectura se sirve de ellas.

Hace algunos años, en colaboración con el profesor Jesús Alegría de la Université Libre de Bruxelles, preparamos una serie de tareas destinadas a evaluar el funcionamiento del procesamiento fonológico de los disléxicos a diferentes niveles y las hemos aplicado en nuestros estudios sobre la dislexia, uno de ellos en colaboración con el profesor Juan Luis Luque de la Universidad de Málaga. Las presento en el cuadro 1.

El procesamiento fonológico es algo complejo, implica diferentes niveles: perceptivo, representacional y productivo, desde la entrada de la información fonológica en el sistema hasta que ésta se recupera y se produce. Podemos utilizar tareas de discriminación fonética, como la tarea de pares mínimos en la que se presentan auditivamente dos sílabas como /bal/ y /pal/, que sólo se diferencian en un rasgo fonético (en este caso la sonoridad de la consonante inicial), para explorar posibles dificultades en la percepción de los sonidos del habla. Para explorar la calidad de las representaciones fonológicas lexicales almacenadas y el acceso a las mismas podemos utilizar tareas de fluidez verbal en las que se pide producir durante un corto espacio de tiempo (20-30 segundos) palabras de una categoría determinada (p.ej. nombres de animales, alimentos, etc.). Es importante en esta tarea elegir una categoría para la que el niño disponga de un vocabulario amplio, de forma que una mala ejecución no se pueda achacar a la carencia de ejemplares en su léxico, sino propiamente a dificultades para su localización y recuperación. Además, las tareas de nombrado rápido, consistentes en ir diciendo de forma rápida los nombres de una serie de imágenes (objetos, colores, letras o números), nos va a servir para los mismos fines. También en esta tarea es muy importante controlar la familiaridad de los ítems ya que lo que interesa medir es la rapidez y no la exactitud en la denominación. La velocidad de nombrado parece ser uno de los mejores indicadores de los problemas fonológicos de base que tienen los disléxicos y pude ser detectado muy tempranamente, incluso antes de que aprendan a leer. También en las tareas de memoria fonológica a corto plazo fracasan algunos disléxicos; en estas tareas se presentan auditivamente series de varias unidades silábicas (p.ej. ba - sa - fa - ca la..) que hay que repetir de forma inmediata en el mismo orden de la presentación. Cuando el mantenimiento preciso de la información fonológica en la memoria falla afectará al procesamiento lector, por ejemplo dificultando el análisis metafonológico pero sobre todo dificultando la extracción del significado en el procesamiento de las frases, para lo que se requiere mantener en la memoria las palabras que las componen.

Finalmente, para la evaluación de la conciencia fonológica nuestra batería de pruebas incluye una tarea de supresión silábica en la

\begin{tabular}{|ll|}
\multicolumn{1}{|c}{ Nivel cognitivo } & \multicolumn{1}{c|}{ Tareas } \\
\hline pperceptivo & $\Rightarrow$ Discriminación (pares min.) \\
(elaboración representaciones fonológicas) & $\ldots$.... \\
$\Leftrightarrow$ representacional & $\Rightarrow$ Fluidez verbal \\
(almacenamiento/acceso representaciones fonológicas) & $\Rightarrow$ Nombrado \\
$\Leftrightarrow$ productivo & $\Rightarrow$ Memoria fonológica \\
(de la representación a la pronunciación) & $\Rightarrow \ldots$ \\
$\Rightarrow$ metafonológico & $\Rightarrow$ Supresión silábica \\
(análisis consciente de la estructura fonológica) & $\Rightarrow$ Identificación fonémica \\
& $\Rightarrow$ Supresión fonémica \\
\hline
\end{tabular}

Cuadro 1.

Funcionamiento del procesamiento fonológico 
que se presentan auditivamente pesudopalabras trisilábicas en las que hay que suprimir una de las sílabas y pronunciar el resto. En cada ítem se especifica la sílaba a suprimir, que puede ocupar cualquiera de las tres posiciones (inicial, final o central). En la similar tarea de supresión fonémica se presentan sílabas de distinta complejidad (CV - VC - CVC - CCV) a las que hay que suprimir alguno de sus fonemas consonánticos. Además, en la tarea de identificación de fonemas se presentan los mismos ítem que en la tarea de supresión pero sólo se pide responder si el fonema consonántico está contenido en el ítem.

La conciencia fonológica es el proceso fonológico que está más relacionado con el aprendizaje de la lectura y en la que más fallan los disléxicos. Hay disléxicos en los que no observamos dificultades graves a nivel de discriminación, de representación y acceso o de memoria y sin embargo fallan en la conciencia fonológica y eso es suficiente para fracasar en el aprendizaje de la lectura.

Seguidamente paso a presentar algunos resultados en estas tareas de alumnos de $2^{\circ}$ a $6^{\circ}$ curso de educación primaria, disléxicos y normolectores (Carrillo \& Alegría, 2009a). Por ejemplo, en la tarea de nombrado de imágenes, la figura 1 muestra la diferencia en las puntuaciones de velocidad (tiempo en segundos) entre los disléxicos (línea superior) y los normolectores (línea inferior). En todos los cursos se advierte que hay un problema en los disléxicos, en la velocidad en el nombrado. En la figura 2, que corresponde a la tarea de fluidez verbal, se representa la media del número de palabras producidas en 30 segundos en cuatro categorías: nombres de animales, de ropa y accesorios para vestir, palabras que comiencen por /s/ y palabras que comiencen por $/ \mathrm{p} /$. Como se puede apreciar, también los disléxicos como grupo, tanto en segundo, tercero, cuarto, quinto y sexto tienen un problema y puntúan significativamente por debajo de los niños normolectores. Igualmente en la tarea metafonológica de supresión de sílabas (p.ej. decir "potarchu" sin decir "tar"), encontramos diferencias significativas entre disléxicos y normolectores (Figura 3), incluso en disléxicos de sexto curso, en los que se podría pensar que no tendrían dificultades para una tarea tan sencilla.

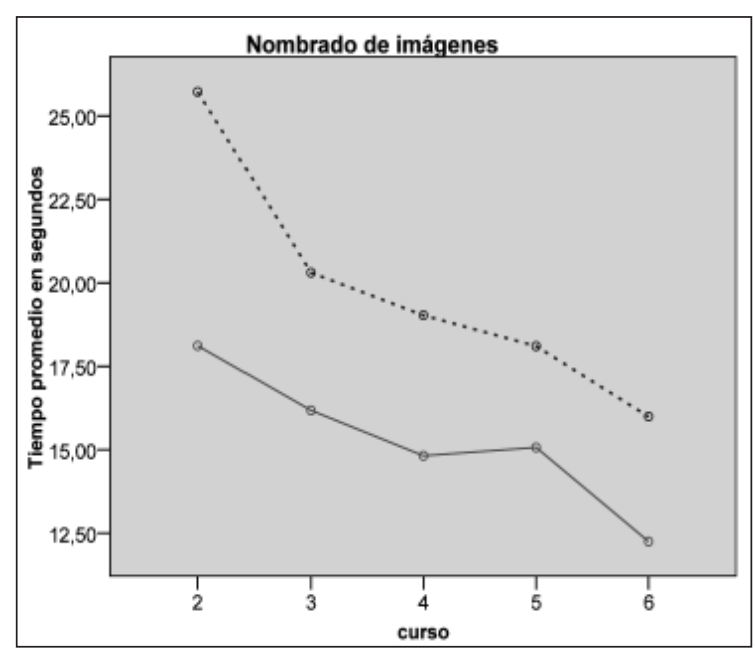

Figura 1

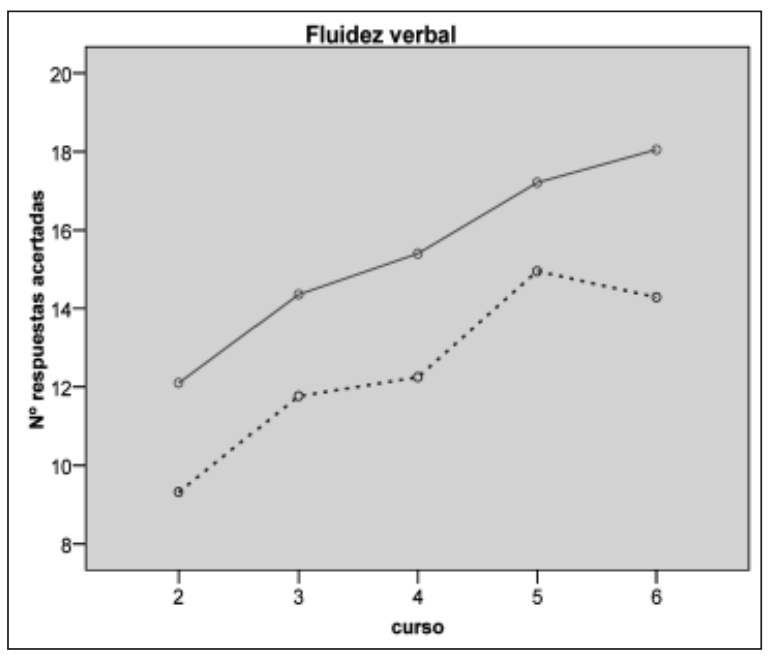

Figura 2

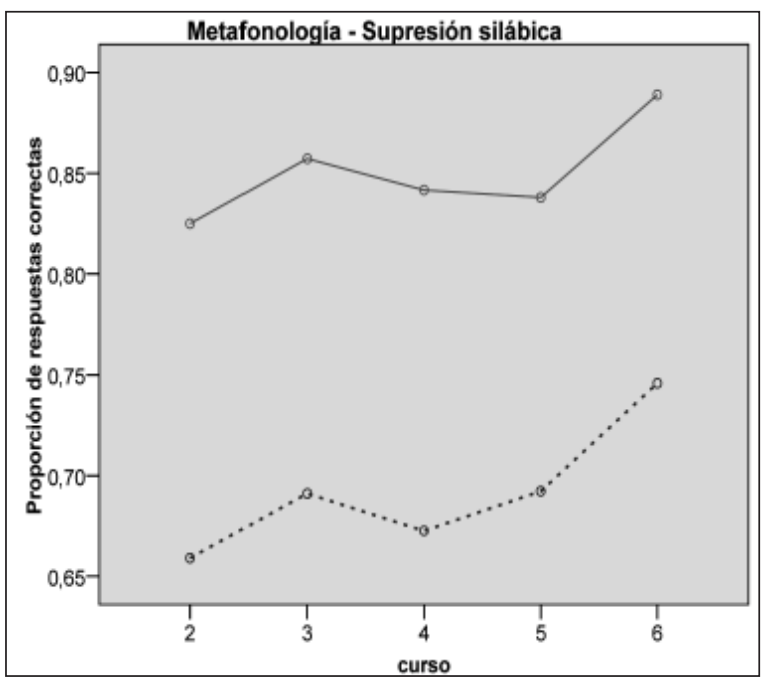

Figura 3 
Este tipo de tareas que no requieren haber aprendido a leer para poder realizarlas, pueden ser aplicables tempranamente en el alumnado preescolar con el fin de detectar los casos con dificultades para realizarlas. Estas dificultades pueden constituir una señal que avisa de posibles dificultades para aprender a leer, sin que quiera decir que en todos estos casos el problema lector pueda llegar a producirse. Aunque la abundante investigación sobre los predictores tempranos del fracaso lector ofrece algunas orientaciones, las más sólidas proceden del estudio del desarrollo metafonológico, mientras que en otras capacidades fonológicas los estudios son menos concluyentes. Sin embargo es necesario que los riesgos de problemas de aprendizaje de la lectura sean detectados tempranamente, ya que se ha comprobado que los tratamientos son más efectivos si se inician en los comienzos de la enseñanza de la lectura. En relación con este punto, se encuentra la cuestión de los métodos de enseñanza, un tema que no trataremos ahora, tan solo señalar la recomendación que se deprende de las investigaciones que comparan las bondades y debilidades de diferentes métodos. Estos estudios indican la gran importancia de la enseñanza del código alfabético y del mecanismo de conversión grafo-fonológica, adquisiciones en las que los disléxicos tienen las mayores dificultades, por lo que necesitan que esta enseñanza esté muy bien planeada y sistematizada.

Con lo comentado hasta ahora he tratado de mostrar que los conocimientos que hoy tenemos sobre la dislexia son sólidos y muestran la necesidad y el camino a seguir para ayudar a los escolares que la padecen. Pero también quiero señalar que estos avances no se corresponden aún con la toma de medidas educativas que lleguen a este alumnado. La información no parece haber llegado a muchas autoridades educativas y es necesario que les llegue, vía las demandas de los centros escolares y también a través de las asociaciones de padres de disléxicos que cada vez están más informadas y con más fuerza para exigir que las necesidades específicas de apoyo educativo de sus hijos sean atendidas. La movilización de estas asociaciones en España está consiguiendo influir en que las medidas de apoyo se vayan incluyendo en las normativas de funcionamiento de los centros educativos.
En la última parte de mi conferencia añadiré algunas conclusiones sobre características de la dislexia en castellano obtenidas en nuestras investigaciones. Ya los resultados de nuestro primer estudio en España (Calvo, 1999) y los obtenidos por Cuadro (2005) en escolares uruguayos convergen al señalar que los problemas más importantes en el reconocimiento de palabras no son de exactitud sino de fluidez, sobre todo cuando comparamos nuestros resultados con los obtenidos en lengua inglesa. En un estudio posterior (Carrillo \& Alegría 2009b) comparamos a 60 escolares disléxicos de $3^{\circ}$ a $6^{\circ}$ curso con 65 normolectores de los mismos cursos. El grupo de disléxicos tenía una media de 14,4 en el test TECLE de eficiencia lectora, mientras que la media del grupo de normolectores era de 30,4. Esta prueba está baremada en población uruguaya y requiere leer en silencio y completar una serie de frases eligiendo la respuesta adecuada entre cuatro opciones (dos palabras y dos pseudopalabras muy similares ortográficamente). La puntuación en el test es el número de frases correctamente completadas en cinco minutos. Para evaluar el funcionamiento de los dos mecanismos de identificación de palabras aplicamos una prueba de lectura en voz alta de palabras frecuentes y otra de lectura de pseudopalabras, tomando en cuenta tanto la exactitud como el tiempo empleado. Los resultados en ambas medidas y tanto en la lectura de palabras como en la pseudopalabras muestran que los disléxicos progresan con el curso, sin embargo siempre se mantienen significativamente por debajo de los normolectores, y ni siquiera los disléxicos de $6^{\circ}$ consiguen puntuaciones similares a los normolectores de $3^{\circ}$. Para obtener una medida de eficiencia tomando en cuenta tanto la exactitud como el tiempo, dividimos el número de aciertos por el tiempo en segundos y pudimos observar que las diferencias en estas medidas eran más pronunciadas en la lectura de palabras que en la de pseudopalabras. Estos resultados dan lugar a que el efecto de lexicalidad (la diferencia entre lectura de palabras y pseudopalabras) resulte mucho más acusado en los normolectores, lo que nos lleva a concluir que la mayor desventaja en los disléxicos se sitúa en el uso del mecanismo ortográfico. Los normolectores leen las palabras con mucha mayor eficiencia que los disléxicos porque 
disponen de buenas representaciones ortográficas, mientras que los disléxicos tienen que apoyarse en el mecanismo fonológico, incluso para leer las palabras frecuentes. Además, la desventaja de los disléxicos en el mecanismo ortográfico se puso claramente de manifiesto en una tarea de dictado de palabras frecuentes conteniendo correspondencias fonema-grafema inconsistentes (p.ej. avión cuyo fonema /v/ puede ser escrito con "v" o con "b").

Sobre la base de estos resultados podemos concluir que los disléxicos de lengua castellana presentan problemas tanto en el mecanismo fonológico de conversión de grafemas en fonemas como en el mecanismo ortográfico lexical. A sus problemas de exactitud al aplicar la conversión grafo-fonológica se añaden los de velocidad, con el resultado de un desarrollo muy pobre de su léxico ortográfico. Si a estos resultados añadimos los comentados anteriormente en las tareas fonológicas de discriminación fonética, fluidez verbal, nombrado rápido, memoria fonológica y metafonología, podemos afirmar que también en nuestra lengua los problemas de los disléxicos tienen su origen en algún déficit en el procesamiento fonológico. Así pues, con independencia de la mayor o menor transparencia de las lenguas, en todas las de escritura alfabética se observan similares problemas, problemas que la actual teoría fonológica de la dislexia interpreta como la causa de sus dificultades lectoras.

En resumen, los resultados confirman la dificultad de los disléxicos en la lectura de palabras. Las dificultades están en los dos mecanismos de lectura: en el fonológico y en el ortográfico.
Podemos derivar la idea de que la dificultad se origina en el mecanismo fonológico que es el motor del aprendizaje, pero que llega a ser más acusada, más dramática en el mecanismo ortográfico, que es el que directamente impide la fluidez lectora. Además, los disléxicos, debido a su propia dificultad, practican poco la lectura, lo que constituye un hándicap añadido. Mientras un normolector simplemente va a mejorar su lectura leyendo y su ruta ortográfica se va enriqueciendo de manera continua y sin esfuerzo, en el disléxico las dificultades para leer, derivadas de sus problemas en la ruta fonológica, le llevan a leer muy poco y mal sin posibilidades de enriquecer su léxico ortográfico.

He llegado al final, muchísimas gracias

\section{REFERENCIAS}

Calvo, A.R. (1999). Adquisición de la lectura en lengua castellana: Perfiles cognitivos de aprendices con dificultades. (Tesis Doctoral). Universidad de Murcia, España

Carrillo, M.S. \& Alegría, J. (2009a). Exploración de habilidades fonológicas en escolares disléxicos: teoría y práctica. Revista de Logopedia, Foniatría y Audiología, 29, 105-120.

Carrillo, M.S. \& Alegría, J. (2009b). Mecanismos de identificación de palabras en niños disléxicos en español: ¿Existen subtipos? Ciencias Psicológicas, 3 (2), 135-152.

Cuadro, A. (2005). Caracterización de los malos lectores en relación a los buenos lectores en niño uruguayos. (Tesis Doctoral). Universidad de Murcia, España

Frith, U. (1999). Paradoxes in the definition of dyslexia. Dyslexia, 5,192-214.

Share, D. L. (1995). Phonological recoding and self-teaching: Sine qua non of reading acquisition. Cognition, 55, 151-218.

1 (N. de la Ed.) Conferencia dictada por la Prof. Dra. Marisol Carrillo el 20 de junio de 2012 en el marco de las actividades de los programas de Maestría en Psicología Educacional y de Postgrado de Especialización en Psicología Educacional (revisada por la autora). Profesora invitada por el Departamento de Psicología del Desarrollo y Educación, de la Facultad de Psicología de la Universidad Católica del Uruguay.

La Prof. Marisol Carillo, Titular de la Facultad Psicología y de Educación de la Universidad de Murcia, España, es maestra y doctora en psicología. Desarrolla su tarea académica y de investigación en ámbitos educativos, con una rica y amplia experiencia que le permite ofrecer esa especial conjunción de teoría y práctica.

Para citar este artículo:

Carrillo, M. (2012). La dislexia: bases teóricas para una práctica eficiente. Ciencias Psicológicas VI (2): $185-194$. 